\title{
Attending Home Care Patients in Primary Care Using a Smartphone Application (WhatsICS): a Feasibility Study
}

\begin{abstract}
Francesc X. Marin-Gomez 1,2, Josep Vidal-Alaball1,3, Francesc Garcia Cuyàs 2,4,5,6, Ramon Reig-Bolaño 2
\end{abstract}

\section{Abstract}

Background: Provision of care to patients with chronic diseases at their homes remains a great challenge for modern health care systems. Smartphone applications are indicated as one of the strategies that could improve care delivery to this group of patients. The aim of this study is to investigate the feasibility and usability of a proprietary application with a messaging service used by a primary care team attending chronic patients mainly at their homes.

Methods: A Cross-sectional pilot study of a smartphone application to communicate amongst clinicians. Primary care practices in Tona, Spain, were recruited during a period from January to December 2016. Clinicians used WhatsICS to communicate during their home visits for 12 months. We studied the patterns of use, response time and types of communication. To explore barriers and enablers, semi-structured interviews were conducted with selected nurses, social worker and general practitioners.

Results: Two nurses, two practitioners and a social worker were recruited and more than 1,000 hours of communication were recorded on 163 patients, generating 5,820 communication events. Nurses initiated the majority of communications (59.79\%); these communications were mainly for the purpose of receiving instructions from practitioners and for coordination (66.6\%). The communications were made on weekdays, from Monday to Friday, and between 7:30 a.m. and 9:30 p.m. (99.73\%). Participants felt that WhatsICS helped streamline and improve home-based care.
1 Gerència Territorial de la Catalunya Central, Catalan Health Institute, Sant Fruitós de Bages, Barcelona, Spain.

2 Digital Care Research Group, University of Vic-Central University of Catalonia, Vic, Barcelona, Spain.

3 Mental Health and Social Innovation Research Group, University of VicCentral University of Catalonia, Vic, Barcelona, Spain.

4 TicSalut Foundation's, Departament de Salut, Generalitat de Catalunya, Mataró, Barcelona, Spain.

5 Department of General Surgery, Autonomous University of Barcelona, Barcelona, Spain.

6 Chair in ICT and Healthcare, University of Vic-Central University of Catalonia, Vic, Barcelona, Spain.

Contact information:

Francesc X. Marin-Gomez.

Address: Servei d'Atenció Primària Osona, Institut Català de la Salut, Plaça Divina Pastora 7, 08500, Vic, Barcelona, Spain.

$\equiv 32513 \mathrm{fmg@comb.cat}$ 
Conclusions: WhatsICS is safe technologically and accepted as a communication tool for professionals. This study establishes the basis for future implementations of this tool to improve the care of chronic patients at home through smartphones.

\section{Keywords}

Communication; Chronic patient; MHealth; Primary care; Homecare.

\section{Introduction}

The care of chronically ill patients has become a major issue for health care systems of developed countries, which by their design, are not prepared enough to deal with the demand that these patients are now generating and will generate, even more, in the future [1]. According to a recent United Nations report, it is estimated that by 2050 the percentage of people over 60 will be around $21 \%$ of the world population and that $34 \%$ of the Europeans will be over 65 [2]. Scientific, health and social advances have contributed to this increase in the life expectancy of our societies and this has a growing impact on the demand and provision of health services. On the other hand, elderly people prefer to get old in their homes or at least in their community in which they are living [3-5]. Consequently, it is necessary to redefine care models to prioritize primary care in the community $[6,7]$.

Along with sociodemographic changes, a "technological" revolution is undergoing and telemedicine, in particular m-health that favours personalization of care, facilitates that elderly patients continue to live in the comfort of their home while receiving adequate and ongoing care. Early initiatives have emerged to reform the type of care provided to the chronically ill, with a new structured, proactive and multidisciplinary approach, based on primary care and supported by a range of specialists, including geriatricians, community nurses, mental health and rehabilitation professionals; working in partnership with caregivers and social care professionals and sharing information, assessments, policies, training and learning [7-9]. However, while those technologies can greatly facilitate the care of the chronically ill, the communication methods used by health professionals often evokes to a period before the introduction of smartphones and social networks. The old communication systems have stopped being effective and smartphones are becoming new tools to increase and facilitate connections between health professionals. According to a recent UK study, over $90 \%$ of General Practitioners use smartphones and/or Tablet PCs during daily practice and feel comfortable with this [10]. WhatsApp is a popular mobile messaging application available on all smartphone platforms which is a model of innovation as a communication system in different disciplines, including health [11, 12]. Although WhatsApp seems to be a good tool to use in communication among clinicians, different authors have questioned their clinical safety [13, 14].

This study aims to evaluate, for the first time, the use of WhatsICS, a proprietary application that facilitates a technologically secure communication among members of a multidisciplinary team that cares for chronic patients at home. 


\section{Methods}

\section{Study Design}

We used a cross-sectional pilot study of a smartphone-based communication application in order to analyse the communication events among the team members of a primary care centre located in Tona (Barcelona) and we performed interviews to evaluate their satisfaction. The study was conducted between January 2016 and December 2016 and was approved by the University Institute in Primary Care Research Jordi Gol Ethics Committee (P16/178).

The application used (WhatsICS) is a Catalan Health Institute proprietary application that provides instant communication between health professionals in a group or individually and allow to share messages, videos, photos, voice notes, locations or handmade notes [15]. Data is stored in private secure servers owned by the public health care department to ensure privacy and preservation of health data, complying with international data protection laws. Devices' data is only synchronized when accessed through a logged registered account.

A convenience sample of two practice nurses, two general practitioners and a social worker from a primary care centre were recruited and received face-to-face training from a member of the research team on the use of the application. This training involved an initial session of approximately 45 minutes and subsequent support as required.

All communications performed relating to people attended at home by participants during the period of the study were eligible for inclusion. Professionals recruited were notified of their participation in the study with an Information Sheet and provided verbal consent which was documented on a consent log.

Data about the communications were collected, including initiators and receivers, types and clinical domains of communication used and response times according to the different types of communication, domains and clinical grades.

\section{Analysis and statistics}

In order to analyse the feasibility of using the application in primary care we explored different outputs of usability such as rates and characteristics of the initiator and recipient of the communications, their response time, the type of communication and the clinical domain of each episode. The contents of the messages were collected weekly through the web platform of the app and after all identifying data from the patients were eliminated, a mining procedure was carried out of the remaining texts. The study involved the entire population assisted at home by the working group, eliminating the potential for participant bias. The uninterrupted collection of data implies that selection bias was not a problem either. There was no observer bias or measurement bias in the ability to record.

Communication events were analysed using SPSS (version 18; IBM); Statistical significance was taken when $\mathrm{P}<0.05$. Data on the communication frequency were analysed using the chi-square test and data on response times were analysed using Kruskal-Wallis test. The analysis of communication and clinical domains were carried out through the program Atlas.ti 7.5.7.

To understand the relevant barriers and enablers to use the application in primary care, a detailed process evaluation was carried out. Semi-structured interviews were conducted by telephone to recruited practice nurses, general practitioners and the social worker. Interviewees provided written informed consent. Interviews were audio-recorded, transcribed and analysed thematically by the research team. The analysis explored participants' views on the use of the smartphone application by primary care professionals during their working period. The interviews were completed when thematic saturation was achieved. The research team discussed and refined the analysis to reach a final consensus on the main themes in terms of barriers and enablers. 


\section{Results}

More than 1,000 hours of clinical communication were recorded during the 12 months' period of the study, producing 5,820 communication events. Communications occurred mostly on weekdays (Monday until Friday) and the most frequent communication days were Friday (31.37\%) and Monday (25.6\%), between 7:30 and 21:30 pm (99.73\%) (Table 1). The number of communications fell for all participants during the period ranging from August to September (6.25\%; CI95 5.63-6.88), corresponding to the summer holiday period (Figure 1)

Table 1. Characteristics for 5,820 communications.

\begin{tabular}{|l|c|c|c|c|c|}
\hline \multirow{2}{*}{ Variables } & \multirow{2}{*}{ Number } & $\%$ & \multicolumn{2}{c|}{ Cl95\% } \\
\cline { 4 - 6 } & & & & low & high \\
\hline Weekday & & & & \\
\hline Monday & 1,490 & 25.60 & 24.48 & 26.72 \\
\hline Tuesday & 933 & 16.3 & 15.09 & 16.97 \\
\hline Wednesday & 552 & 9.48 & 8.73 & 10.24 \\
\hline Thursday & 1,018 & 17.49 & 16.52 & 18.47 \\
\hline Friday & 1,826 & 31.37 & 30.18 & 32.57 \\
\hline Saturday & 1 & 0.02 & -0.02 & 0.05 \\
\hline Communication & & & & & \\
\hline Before 07:30 & 1 & 0.02 & -0.02 & 0.05 \\
\hline 07:30 to 15:30 & 5456 & 93.75 & 93.12 & 94.37 \\
\hline 15:30 to 21:30 & 348 & 5.98 & 5.37 & 6.59 \\
\hline After 21:30 & 15 & 0.26 & 0.13 & 0.39 \\
\hline
\end{tabular}

Figure 1: Line chart showing the communication frequency per month for each category.

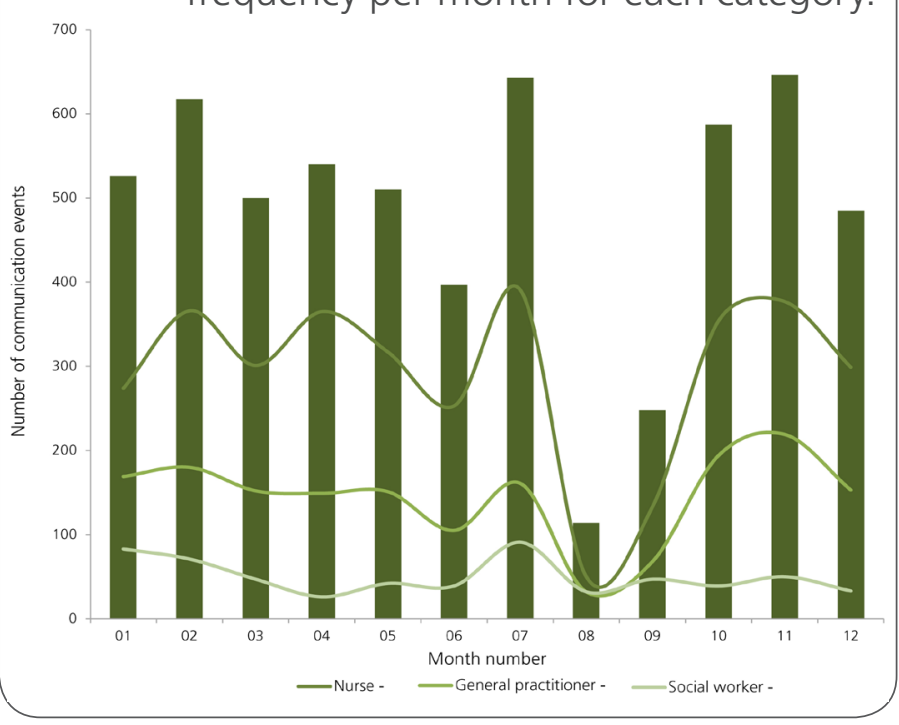

From all communications sent, 59.79\% (C195\% 61.05-58.53) came from nurses, 29.78\% (C195\% 30.95-28.60) from general practitioners and $10.31 \%$ (C195\% 11.09-9.53) from the social worker.

Most of communications did not have a specified receiver or had multiple receivers, so they were attributed to the "team" and grouped together, this represented the largest number of communication events with 79.81\% (CI95\% 80.84-78.78), followed by the communications addressed to physicians 9.45\% (C195\% 10.20-8.70), nurses 8.81\% (C195\% 9.54-8.09) and social worker 1.92\% (CI95\% 2.281.57). The communication pattern of the team during the study is shown in Figure 2.

Figure 2: Diagram showing the frequency and direction of communication events.

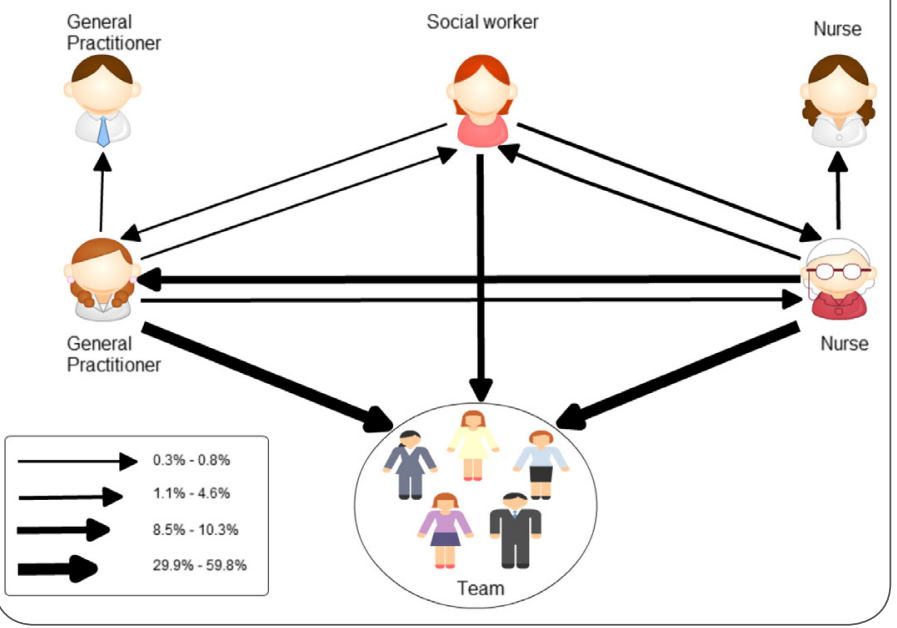

The messages' contents were classified in four types of patterns: clinical questions, coordination, training and administrative question [16, 17]. Coordination issues were the most common type of communication events 40.31\% (CI95\% 41.57-39.05); followed by clinical questions 37.20\% (C195\% 38.44-35.96). The clinical questions ( $n=2,165 ; \chi^{2}=$ $6.114 ; P=.047)$ were mainly formulated by nurses (61.71\%) and the administrative questions $(n=60$; $\left.\chi^{2}=29.195 ; P=0.000\right)$ by practitioners $(40 \%)$. The "team" was the recipient of the largest number of messages $\left(n=2,551 ; \chi^{2}=24,195 ; P 0.000\right)$ and practitioners (52.97\%) answered most clinical questions $\left(n=357, x^{2}=24.111, P<.000\right)$. Table 2 
Table 2. Types and professional categories in communications.

\begin{tabular}{|c|c|c|c|c|c|c|c|c|c|c|c|c|c|c|c|c|}
\hline \multirow{3}{*}{ Variables } & \multirow{3}{*}{$\mathbf{N}$} & \multirow{3}{*}{$\%$} & \multicolumn{6}{|c|}{ Senders } & \multirow{3}{*}{$p x^{2}$} & \multicolumn{6}{|c|}{ Receivers $^{a}$} & \multirow{3}{*}{$p x^{2}$} \\
\hline & & & \multicolumn{2}{|c|}{ Nurses } & \multicolumn{2}{|c|}{ Practitioner } & \multicolumn{2}{|c|}{ Social worker } & & \multicolumn{2}{|c|}{ Nurses } & \multicolumn{2}{|c|}{ Practitioner } & \multicolumn{2}{|c|}{ Social worker } & \\
\hline & & & $n$ & $\%$ & $n$ & $\%$ & $n$ & $\%$ & & $n$ & $\%$ & $n$ & $\%$ & $\mathrm{n}$ & $\%$ & \\
\hline \multicolumn{17}{|c|}{ Communication content } \\
\hline Clinical & 2,165 & 37.2 & 1,336 & 61.71 & 607 & 28.04 & 222 & 10.25 & 0.047 & 261 & 38.72 & 357 & 52.97 & 56 & 8.31 & 0.000 \\
\hline Coordination & 2,346 & 40.31 & 1,373 & 58.53 & 723 & 30.82 & 250 & 10.66 & 0.268 & 313 & 42.94 & 348 & 47.74 & 68 & 9.33 & 0.716 \\
\hline Training & 46 & 0.79 & 31 & 67.39 & 9 & 19.57 & 6 & 13.04 & 0.295 & 8 & 40 & 9 & 45 & 3 & 15 & 0.699 \\
\hline Administrative & 60 & 1.03 & 19 & 31.67 & 24 & 40 & 17 & 28.33 & 0.000 & 11 & 52.38 & 6 & 28.57 & 4 & 19.05 & 0.141 \\
\hline Dther & 2,397 & 41.19 & & & & & & & & & & & & & & \\
\hline
\end{tabular}

a: Four messages excluded for being close to the end of study and with no answer yet $(N=1,171)$.

Table 3. Response time by professional categories and type of message.

\begin{tabular}{|c|c|c|c|c|c|c|c|c|c|}
\hline \multirow{3}{*}{ Variables } & \multirow{3}{*}{ Mean } & \multirow{3}{*}{ IC95\% } & \multicolumn{6}{|c|}{ Respondents } & \multirow{3}{*}{$\mathrm{pH}(2)$} \\
\hline & & & \multicolumn{2}{|c|}{ Nurses } & \multicolumn{2}{|c|}{ Practitioner } & \multicolumn{2}{|c|}{ Social worker } & \\
\hline & & & Mean & IC95\% & Mean & IC95\% & Mean & IC95\% & \\
\hline \multicolumn{10}{|l|}{ Time in hours } \\
\hline Clinical & 1.5 & $1.16-1.84$ & 1.51 & $0.94-2.08$ & 1.41 & $0.98-1.85$ & 2.01 & $0.70-3.32$ & 0.004 \\
\hline Coordination & 1.34 & $1.05-1.62$ & 1.35 & $0.89-1.81$ & 1.16 & $0.80-1.52$ & 2.18 & $0.91-3.45$ & 0.001 \\
\hline Training & 1.97 & $0-4.48$ & 1.12 & $0-3.22$ & 3.25 & $0-9.16$ & 0.40 & $0-1.93$ & 0.290 \\
\hline Administrative & 1.12 & $0.53-1.71$ & 0.96 & $0-1.96$ & .83 & $0-1.67$ & 1.99 & $0.04-3.93$ & 0.297 \\
\hline Other & 2.50 & $1.74-3.26$ & 2.21 & $1.28-3.14$ & 3.15 & $1.65-4.65$ & 2.02 & $0-4.76$ & 0.271 \\
\hline All messages ${ }^{a}$ & 1.65 & $1.39-1.91$ & 1.66 & $1.25-2.08$ & 1.48 & $1.12-1.84$ & 2.43 & $1.41-3.44$ & 0.000 \\
\hline
\end{tabular}

The analysis of the response times between the categories showed that there was a statistically significant difference in the response time of different types of professionals $[H(2)=15,608 ; P=0.000]$, with an average response time of 1.48 (CI95 1.121.84) hours for general practitioners, 1.66 (C195 1.25-2.08) for nurses and 2.43 (1.4-3.44) for the social worker. Subgroup analysis revealed significant differences between the professional category and the response time for clinical questions in which practitioners responded faster than nurses and social worker $[H(2)=11.199 ; P=0.004]$. There was also a significant interaction between the professional category and the response time for coordination questions in which nurses responded faster than general practitioners and social worker $[\mathrm{H}(2)=$ 15.036; $P=0.001]$. Table 3

\section{Qualitative results}

In total, 5 semi-structured interviews were conducted across the two practices participating, comprising two nurses, two GPs and a social worker. Interviews ranged from 20 to 45 minutes. Key barriers and enablers for each group are summarized

\section{in Table 4.}

Nurses believed that the possibility of sending a message from the patients' home, getting a quick response was very useful:

It's perfect because you can comment on something with a colleague immediately, you do not have to look for him, you do not have to meet him, it is easy and saves a lot of time and it speeds up the visit... I recommend it 
Table 4. Qualitative results.

\begin{tabular}{|c|c|c|}
\hline Barriers & & Enablers \\
\hline Demands attention at any time & \multirow{4}{*}{ Practitioners } & Easy to use; similar to WhatsApp \\
\hline \multirow{2}{*}{$\begin{array}{l}\text { Does not allow adding information to } \\
\text { medical records }\end{array}$} & & Improves control and supervision of patients. \\
\hline & & Allows colleagues to consult and sharing doubts. \\
\hline Difficulties of handling (some instructions) & & No interruptions like with the phone \\
\hline Use of private mobile & \multirow{4}{*}{ Nurses } & High level of confidence \\
\hline $\begin{array}{l}\text { No remuneration for telephone data } \\
\text { consumption rate. }\end{array}$ & & Good for following patients at home \\
\hline $\begin{array}{l}\text { No protocol for dealing with abnormal } \\
\text { situations. }\end{array}$ & & Very quick responses from practitioners \\
\hline Security doubts & & Safer than other applications for communications (WhatsApp) \\
\hline Network problems in remote homes. & \multirow{3}{*}{$\begin{array}{l}\text { Social } \\
\text { worker }\end{array}$} & \\
\hline Loss of contact with some patients & & he team \\
\hline $\begin{array}{l}\text { Insufficient planning to allow time for } \\
\text { learning correct use }\end{array}$ & & Obtain patient information without having to look for clin \\
\hline
\end{tabular}

General practitioners were in favour of using an application that allowed them to establish better control and supervision:

It grants a secure communication and it is much more practical to use WhatsICS than having to receive calls that continuously interrupt what you are doing... if you have a group and you share doubts about a patient this is the equivalent of commenting on the cases with the colleagues

Social worker considered that WhatsICS facilitated the communication between the team and allowed to inform about patient's needs quickly.

It's a way of being several kilometres away and if you need it, you can communicate with the team and you know that a person or the team will respond to what you need... it's a great advantage.

All team members were in favour of continuing using WhatsICS in the future. When asked about the use of images sent by the application, they did not find any problem to make diagnoses using a picture taken from patients.

\section{Discussion}

\section{Main findings}

The results of this study provide a new and detailed examination of communication among members of a multidisciplinary primary care team through an smartphone's application and respond to the current need to evaluate new methods of communication in primary care [18].

\section{Interpretation of the study: Results in relation to existing literature}

Studies have shown that patients can suffer considerable damage due to poor communication among health professionals $[19,20] 6$ fellows, 3 residents, but a few number of them have evaluated the response time in their communications and none of them have been done in primary care. The use of smartphone applications represents a successful technological innovation that is replacing other more rudimentary methods of communication and can improve efficiency in clinical decision-making and quality of home-based practice.

Although some professionals fear that a tool like WhatsICS could require their attention during nonworking hours, the study shows that most com- 
munications are conducted during working hours. The team used the application only during working days, which is why only records were obtained in 198 days (80\% of working days) instead of all calendar days. During the summer months, when team members took turns to cover their holidays, there was a reduction in the frequency of communications that recovered afterwards.

The study shows that clinical questions by nurses are answered faster than other types by practitioners. Nurses need to have a quick response from practitioners in other to feel secure in managing alone clinical demands from patients at their homes. Mobile-based innovations, such as our application, show that smartphone communication tools are effective in improving the need for multidisciplinary care for chronic patients at home [21]. Further technological development of health care communication systems will be necessary to include the integration of direct access to patient's clinic information [22].

\section{Strengths and limitations}

The fact that WhatsICS is a proprietary application with adequate security and hard encryption systems, coupled with the fact that information is stored and maintained in public health servers, responds to the current concern about security guarantees of mobile messaging services in the transfer of sensitive data. The main limitation of the study could be that it was carried out, for reasons of feasibility, in only one primary care centre, which is also involved in other projects relating to the management of chronically ill patients, and this could affect the external validity of the study.

\section{Implications for clinical practice}

Smartphone application was accepted as a simple and efficient innovation to communicate within the team. Significant benefits were perceived through a system in which team members had a constant view of activities performed without active interference, allowing nurses to develop a degree of clinical independence with minimal risk for patient safety. Most communications were initiated by nurses and responded to team coordination needs. The qualitative analysis of the team's perceptions allowed a detailed exploration on the crucial role of relationship between professional categories within the team. According to the interviewees' opinion, WhatsICS increases the autonomy in decision making mainly by nurses, under the supervision of the general practitioner and contributes to improve the transmission of information relating to patients.

\section{Conclusions}

WhatsICS is a technologically safe and well accepted communication tool for professionals. This study establishes the basis for future implementation of this tool to improve chronic patient's care at home through the technology of smartphones.

\section{Acknowledgments}

The authors gratefully acknowledge the participation of the general practitioners, nurses, social worker and administrative staff from the Complex Care Unit in the Health Care Centre of Tona. The authors also want to acknowledge the collaboration of Àngels Calvet Canaleta from the Office of Mobility of the Institut Català de la Salut.

\section{Key messages}

- Proprietary health smartphone applications are safe technologically and well accepted by primary care professionals.

- Smartphone applications for communications amongst primary care professionals are especially useful on attending chronic patients at their homes.

- Safe smartphone applications allow nurses increase their degree of clinical independence with a quick response and minimal risk for patient safety. 


\section{Disclosure statement}

The authors report no conflicts of interest. The authors alone are responsible for the content and writing of the paper.

\section{Prior presentations}

Abstracts describing preliminary results were presented at the following meeting: 16th International Conference on Integrated Care (ICIC16), Barcelona, Spain, 2016 (oral presentation).

\section{References}

1. New York, NY: United Nations D of E and SA. DESA, World Population Ageing 2015: Highlights, 2015. 2015.

2. Unidas F de P de N, (UNFPA), Nueva York y HelpAge International L. Envejecimiento en el Siglo XXI: Una Celebración y un Desafío. 2012.

3. Li Ping Goh SH and DBR and PD. Public Housing in Singapore: Residents' Profile, Housing Satisfaction and Preferences: HDB Sample Household Survey 2013. 2014

4. TA K. Home and community preferences of the 45+ Population. Washington (DC): AARP. 2010.

5. Joan Costa-Font, David Elvira OM-M. "Ageing in Place"? Exploring Elderly People's Housing Preferences in Spain. Urban Stud 2009; 46:295-316. doi: http://dx.doi.o https://doi. org/10.1177/0042098008099356.

6. Beswick AD, Rees K, Dieppe P, Ayis S, Gooberman-Hill R, Horwood J, et al. Complex interventions to improve physical function and maintain independent living in elderly people: a systematic review and meta-analysis. Lancet (London, England) 2008; 371:725-35. doi:10.1016/S0140-6736(08)60342-6.

7. Huss $A$, Stuck AE, Rubenstein LZ, Egger M, Clough-Gorr KM. Multidimensional preventive home visit programs for community-dwelling older adults: a systematic review and meta-analysis of randomized controlled trials. J Gerontol A Biol Sci Med Sci 2008; 63:298-307.

8. Pinelle D, Gutwin C. Supporting collaboration in multidisciplinary home care teams. Proc AMIA Symp 2002:617-21.

9. Peebles E, Subbe CP, Hughes P, Gemmell L. Timing and teamwork-an observational pilot study of patients referred to a Rapid Response Team with the aim of identifying factors amenable to re-design of a Rapid Response System. Resuscitation 2012; 83:782-7. doi:10.1016/j.resuscitation.2011.12.019.

10. Yaman H, Yavuz E, Er A, Vural R, Albayrak Y, Yardimci A, et al. The use of mobile smart devices and medical apps in the family practice setting. J Eval Clin Pract 2016; 22:290-6. doi:10.1111/ jep.12476.

11. Mars M, Scott RE. WhatsApp in Clinical Practice: A Literature Review. Stud Health Technol Inform 2016; 231:82-90.

12. Muntaner A, Vidal-Conti J, Borràs PA, Cantallops J, Ponseti FJ, Palou P. Uso de WhatsApp para la disminución de factores de riesgo cardiovascular en personas mayores. Rev Andaluza Med Del Deport 2015; 8:36-7. doi:10.1016/j.ramd.2014.10.043.
13. Schrittweiser SF, Kieseberg $P$, Leithner $P$ et al. Guess who's texting you? Evaluating the security of smartphone messaging applications. 2012.

14. Watson L, Pathiraja F, Depala A, O'Brien B, Beyzade S. Ensuring safe communication in health care: a response to Johnston et al on their paper "Smartphones let surgeons know WhatsApp: an analysis of communication in emergency surgical teams." Am J Surg 2016; 211:302-3. doi:10.1016/j.amjsurg.2015.04.017.

15. Marin X, Epelde A, Segalés M, Arjona M, Clopés M, Blazquez $C$, et al. Efficacy of a smartphone app (WhatsICS) for communication amongst health care professionals attending patients with chronic diseases. Int J Integr Care 2016; 16:179. doi:10.5334/ijic. 2727.

16. Wani S, Rabah S, AlFadil S, Dewanjee N, Najmi Y. Efficacy of communication amongst staff members at plastic and reconstructive surgery section using smartphone and mobile WhatsApp. Indian J Plast Surg 2013; 46:502. doi:10.4103/09700358.121990.

17. Jenaro A. Fernández-Valencia, Elena Salas, Jorge Egea, Maria Cinta Pinyol, Montserrat Orench, Montserrat Tió, Montserrat Díaz, Guillem Bori XG. Whatsapp messenger for surgical team coordination. Initial experience of a hip team in a third level hospital. Int J Adv Jt Reconstr 2015; 2:23-6.

18. McElroy LM, Ladner DP, Holl JL. The role of technology in clinician-to-clinician communication. BMJ Qual Saf 2013; 22:981-3. doi:10.1136/bmjqs-2013-002191.

19. Lingard L, Espin S, Whyte S, Regehr G, Baker GR, Reznick $R$, et al. Communication failures in the operating room: an observational classification of recurrent types and effects. Qual Saf Health Care 2004; 13:330-4. doi:10.1136/qhc.13.5.330.

20. Nagpal K, Arora S, Abboudi M, Vats A, Wong HW, Manchanda $C$, et al. Postoperative handover: problems, pitfalls, and prevention of error. Ann Surg 2010; 252:171-6. doi:10.1097/ SLA.0b013e3181dc3656.

21. Brigic A, Bloor J, Clark A, Thomas M. How will health-care organizations meet venous thromboembolism targets? $\mathrm{Br} \mathrm{J}$ Hosp Med (Lond) 2011; 72:35-8.

22. Whittaker R. Issues in mHealth: Findings From Key Informant Interviews. J Med Internet Res 2012; 14:e129. doi:10.2196/ jmir.1989.

Publish in International Archives of Medicine

International Archives of Medicine is an open access journal publishing articles encompassing all aspects of medical science and clinical practice. IAM is considered a megajournal with independent sections on all areas of medicine. IAM is a really international journal with authors and board members from all around the world. The journal is widely indexed and classified Q2 in category Medicine. 